\title{
An Event-Related Brain Potential Analysis of Visual Word Priming Effects
}

\author{
Colin M. Brown,* Peter Hagoort,* and Dorothee J. Chwilla† \\ *Max Planck Institute for Psycholinguistics, Nijmegen, The Netherlands; and †Nijmegen \\ Institute for Cognition and Information, University of Nijmegen, Nijmegen, The \\ Netherlands
}

\begin{abstract}
Two experiments are reported that provide evidence on task-induced effects during visual lexical processing in a prime-target semantic priming paradigm. The research focuses on target expectancy effects by manipulating the proportion of semantically related and unrelated word pairs. In Experiment 1, a lexical decision task was used and reaction times (RTs) and event-related brain potentials (ERPs) were obtained. In Experiment 2, subjects silently read the stimuli, without any additional task demands, and ERPs were recorded. The RT and ERP results of Experiment 1 demonstrate that an expectancy mechanism contributed to the priming effect when a high proportion of related word pairs was presented. The ERP results of Experiment 2 show that in the absence of extraneous task requirements, an expectancy mechanism is not active. However, a standard ERP semantic priming effect was obtained in Experiment 2. The combined results show that priming effects due to relatedness proportion are induced by task demands and are not a standard aspect of online lexical processing. (c) 2000 Academic Press
\end{abstract}

Within one of the major research areas of psycholinguistics — visual word processing — quite some discussion has focused on task-specific effects, such as originate from the requirement to make a binary and/or speeded response or to monitor the input for some prespecified letter string. The susceptibility of reaction time (RT) tasks to response strategies has been a particular concern (cf. Besner \& Johnston, 1989; Keefe \& Neely, 1990; Neely, Keefe, \& Ross, 1989; Seidenberg, 1989). What is meant by strategy here is some process that is not necessarily part of ordinary language comprehension and that

The authors thank three anonymous reviewers for their comments and suggestions, as well as Johan Weustink for technical support and Inge Doehring for graphical assistance. This research was in part supported by Grant 560-256-048 from the Netherlands Organization for Scientific Research (NWO).

Address correspondence and reprint requests to Colin Brown, "Neurocognition of Language Processing'” Research Group, Max Planck Institute for Psycholinguistics, P.O. Box 310, NL6500 AH Nijmegen, The Netherlands. 
subjects (consciously or unconsciously) invoke to help them meet the task demands of a particular experimental setting.

The main purpose of this paper is to present new evidence on task-induced effects during visual lexical processing in a semantic priming paradigm. The research uses prime-target pairs and focuses on a comparison of lexical decision and silent reading.

The effect under investigation is the relatedness proportion effect (cf. Fischler, 1977; Neely, 1977; Tweedy, Lapinski, \& Schvaneveldt, 1977). This effect modulates the standard semantic priming effect, in which target words preceded by associatively and/or semantically related primes are responded to faster and with fewer errors, compared to words preceded by unrelated primes (see Neely, 1991, for a review). In the relatedness proportion effect, the size of semantic priming effects increases as the proportion of related word pairs relative to unrelated word pairs in the stimulus list increases. This modulation has been reported both with a lexical decision task (e.g., De Groot, 1984; Neely et al., 1989; Seidenberg, Waters, Sanders, \& Langer, 1984; Shelton \& Martin, 1992) and a pronunciation task (Keefe \& Neely, 1990). It occurs for long but not short prime-target stimulus-onset asynchronies (e.g., Den Heyer, Briand, \& Dannebring, 1983; but see De Groot, 1984). The present paper discusses event-related brain potential (ERP) and RT data on the basis of which it is suggested that the priming mechanism underlying the relatedness proportion effect might not be a natural part of the lexical analysis process, but probably originates from the response requirements of RT tasks.

The discussion of response strategies and their effects has primarily evolved within research using the visual word-word semantic priming paradigm. This research has attempted to explain the semantic priming effect by postulating a number of different priming mechanisms, two of which are claimed to be more or less strategic, in part dependent on the particular RT task being used (usually either lexical decision or pronunciation). Neely and Keefe (1989) present a detailed analysis of semantic priming effects and argue that three different mechanisms are needed to account for the entire range of RT priming effects: (1) automatic spread of activation (ASA), (2) expectancy-induced priming, and (3) semantic matching. The latter two are thought to be open to strategies, although semantic matching has been claimed to be a more natural component of ordinary language comprehension (cf. Neely, 1991).

With ASA it is assumed that links exist between semantically and/or associatively related nodes in the mental lexicon (cf. Collins \& Loftus, 1975). Analysis of a prime word results in activation spreading within the lexicon to nodes representing words that are related in meaning. Due to their enhanced activation, activated nodes need less time for subsequent processing, relative to nonprimed words.

In expectancy-induced priming, subjects generate-under certain circum- 
stances - an expectancy set on the basis of the information contained by the prime. This expectancy set contains potential target words that are semantically related to the prime. If the actual target is a member of this set it will be recognized more quickly. If it is not in the set, recognition will be slowed down. In RT tasks, expectancy-induced priming therefore not only facilitates the processing of expected targets, but it also inhibits the processing of unexpected targets (cf. Becker, 1980; Neely, 1977).

Semantic matching, finally, is a postlexical process in which subjects check for semantic overlap between primes and targets once they have been accessed. Semantic matching is thought to influence the results in the lexical decision task, but not in the pronunciation task. In the lexical decision task it is assumed that subjects bias their decisions according to the result of this matching process. The detection of a relationship between primes and targets leads to a bias to respond "yes." If no relation is detected, then there is a bias to respond "no." Thus, semantic matching results in facilitation for related targets. For unrelated targets, however, semantic matching does not succeed, which induces a bias to respond "'no.' Therefore, the required yes response will be inhibited.

On the basis of an analysis of relatedness proportion effects in both lexical decision and pronunciation, Keefe and Neely (1990) conclude that the relatedness proportion effect " . . . is mediated by an expectancy mechanism that contributes to priming in both the LDT [lexical decision task] and the pronunciation task', (Keefe \& Neely, 1990, p. 296). That is, the presence of a relatively high proportion of related word pairs (e.g., 80\%) induces subjects to generate an expectancy set of potential target words on the basis of the meaning of the prime.

The specific question that is addressed in the following experiments is whether the expectancy mechanism is a task-induced effect, peculiar to the response requirements of RT tasks. An answer to this question is important in order to weigh the implications of particular semantic priming effects (such as those brought about by manipulating relatedness proportion) for a functional characterization of the visual lexical analysis process. If expectancy-induced priming and its effect on RT measures are shown to be a product of the RT task requirements, then the impact of such priming effects on functional models of lexical processing is limited.

To find out whether expectancy-induced priming is a product of RT task requirements, the present study assesses relatedness proportion effects on two dependent measures, RTs and ERPs, under two task conditions: Lexical decision (gathering both RTs and ERPs) and silent reading (gathering only ERPs). In the latter situation subjects are not required to perform any task (hence, no RTs are gathered) other than simply reading the stimuli. This capitalizes on an appealing feature of the ERP method (which it shares with eye-movement recording), namely, that significant effects of independent variables can be obtained in the absence of extraneous and additional task 
demands (see McNamara \& Healy, 1988, for an RT version of " silent reading"; see also Lorch, 1986). The critical comparison, then, is between a manipulation of relatedness proportion under lexical decision and under silent reading conditions, using the same list of stimuli. This enables investigation of the possibly task-dependent nature of the expectancy-induced priming mechanism. If relatedness proportion effects obtain with lexical decision but not with silent reading, then this has implications for the importance of expectancy-induced priming effects with respect to functional models of visual word processing.

In the experiments reported below, subjects were presented with a list of stimuli with either a low (.20) or a high (.80) proportion of related word pairs, and both RTs and ERPs were registered. The RTs served to validate the basic relatedness proportion effect as it has been reported in the RT literature: (1) In the high relatedness proportion list, facilitation of related targets, and inhibition of unrelated targets, relative to a neutral baseline; (2) in the low relatedness proportion list, facilitation of related targets relative to a neutral baseline and no difference between the unrelated and the neutral conditions; (3) overall larger priming (related versus unrelated) in the high compared to the low relatedness proportion list. The ERPs in the lexical decision and the silent reading task serve primarily to assess the influence of task demands, but also to validate the standard semantic priming effect on the brain's electrical activity. This priming effect is predicted to occur at the level of the so-called N400 component of the ERP waveform (Kutas \& Hillyard, 1980).

The N400 is a negative polarity component, with a centroparietal maximum over the scalp, that emerges at about $250 \mathrm{~ms}$ after the onset of word stimulation and that reaches its maximal amplitude at roughly $400 \mathrm{~ms}$. There is ample evidence that the N400 is sensitive to ongoing linguistic analyses. Generally speaking, every word elicits an N400. The particular latency and amplitude characteristics of the N400 depend on the context within which the eliciting word occurs, as well as on specific properties of the word itself (such as its frequency and form class). A large number of studies have shown that the N400 is particularly sensitive to semantic information processing, both in prime-target and in sentential contexts. The standard semantic priming RT effect is mirrored in the N400, where unrelated target words elicit a larger amplitude than related targets. This amplitude difference is referred to as the N400 effect (see Kutas \& Van Petten, 1988, 1994, for reviews). Within the context of the experiments described here, a standard N400 effect as a function of semantic relatedness is predicted.

To the extent that an expectancy-induced priming mechanism is operative, relatedness proportion effects are predicted to emerge as modulations of the amplitude of the N400: The size of the N400 effect should vary as a function of relatedness proportion, with the largest N400 effect in the high proportion list. This prediction is supported by a study reported by Holcomb (1988). 
Holcomb measured ERPs and RTs in a lexical decision task on lists with high and low proportions of semantically related trials. His main finding was that the N400 effect was larger in the high compared to the low proportion list. However, in contrast to the present study, Holcomb's research cannot be used (and was not intended) to assess the nature of the relatedness proportion effect: There was no silent reading comparison in his research.

The remainder of this paper is organized as follows. First, the lexical decision experiment is presented, which shows a semantic priming effect and a modulation of this effect by relatedness proportion, in both the RT and the ERP measures. Second, the validity of this result is assessed in the silent reading experiment. These analyses and discussions focus entirely on the processing of the target word. Following these sections, ERP data are presented on the processing of the prime words. In the experiments reported here, the Dutch word blanco (English translation: blank) is used as the prime in the neutral condition. The ERP data for the primes provide evidence concerning the validity of the stimulus blanco as an appropriately neutral prime. This evidence connects to discussions in the RT priming literature, where it has been something of an issue whether an essentially meaningless real word (such as blank) is to be preferred over a string of nonletter symbols (e.g., asterisks, hash marks) as the neutral prime stimulus and, more in general, whether a truly neutral stimulus can be achieved at all (cf. De Groot, Thomassen, \& Hudson, 1982; Fischler \& Bloom, 1980; Shelton \& Martin, 1992). This issue is examined under General Discussion, following which the remainder of the discussion focuses on the implications of the results obtained for the target words. Since-with the exception of the experimental taskthe stimuli, design, and procedure are the same for the two experiments, a general method section is presented first.

\section{METHOD}

\section{Subjects}

Sixty-eight subjects (mean age 23, $n=24$ men) were paid to participate in the experiments. None of these subjects had participated in any of the stimulus materials norming studies (see Materials). Due to excessive EEG and EOG artifacts, the data of 8 subjects could not be adequately analyzed, leaving a total of 60 subjects, of which half were tested with a lexical decision task and half with a silent reading task. None of the subjects had any neurological impairment or had experienced any neurological trauma according to their responses on a questionnaire. All subjects had normal or corrected to normal vision and were right-handed according to their responses on an abridged Dutch version of the Oldfield Handedness Inventory (Oldfield, 1971). Twenty-five subjects reported left-handed relatives in their immediate family.

\section{Materials}

Two lists of stimuli were constructed, one with a high proportion of related word pairs (.80) and one with a low proportion of related word pairs (.20). Each list consisted of 480 prime- 
target pairs. Half of these pairs had a nonword target, and half had a Dutch word as target. The word pairs consisted of associatively related words (e.g., ship-sailor), of unrelated words (e.g., star-hour), or of word targets preceded by the neutral prime blanco (the Dutch word for blank). Of the 240 nonword targets, 200 were preceded by a word prime (e.g., dog-wunk) and 40 were preceded by the neutral prime. The nonwords were constructed according to the phonotactic constraints of Dutch and were derived from real words by substituting one or two letters. Of the 240 word pairs, 120 are critical test items, on which reaction time and ERP analyses are reported. These 120 items are divided into three sets of 40 related, unrelated, and neutral word pairs.

All targets consisted of one- or two-syllable strings, ranging in length from three to eight letters. The targets in the three sets of 40 critical word pairs were matched on number of syllables and number of letters. The mean word frequency (and standard deviation) based on a corpus of 720,000 words (Uit den Boogaart, 1975) for the 40 targets in the related set was 82 (108), in the unrelated set 62 (106), and in the neutral set 79 (111). The mean length and the mean number of syllables of all targets (both words and nonwords) were matched between the two lists of stimuli. The mean association strength of the related pairs was obtained from published association norms established with a population of 100 students (De Groot, 1980; Lauteslager, Schaap, \& Schievels, 1986) and was 47.4 (15.3). In addition to matching on lexical characteristics, we matched the targets in the three critical sets on the basis of their lexical decision times, gathered in a reaction time pretest in which all targets were presented in isolation. The reason for this additional matching procedure was to reduce spurious betweenset item variance as much as possible. A total of 480 words and 480 nonwords were visually presented in a randomized sequence to 10 subjects and in the reverse order to another group of 10 subjects (using the same procedure as for the main experiments; see Procedure for details; none of these subjects subsequently participated in the main experiments). Subjects had to make a speeded lexical decision on the targets by pushing a YES button as quickly as possible if the target was a word and a NO button if the target was a nonword. The reaction times to word targets obtained in this way were used to match the set of targets in the related, unrelated, and neutral sets on overall absolute reaction time. Targets from the three sets were matched on the basis of the criterion that their reaction times should not differ more than 4 ms.

The two proportion lists were preceded by the same practice sequence of 20 prime-target pairs. Half of the targets were words, paired with related $(n=4)$, unrelated $(n=3)$, and neutral primes $(n=3)$.

\section{Design}

The high and low relatedness proportion lists each contained the same set of 40 critical related, unrelated, and neutral word pairs. To avoid repetition effects, the relatedness proportion manipulation was implemented as a between-subjects factor, as was the task instruction (lexical decision versus silent reading). To realize the two relatedness proportions, different numbers of related and unrelated word pairs were added to the critical word pairs in the high and low relatedness proportion lists. The high relatedness proportion list was made up of 40 critical related word pairs, an additional 120 related word pairs, 40 critical unrelated word pairs, 40 critical neutral word pairs, and 240 word-nonword pairs (of which 40 were preceded by the neutral prime). So, this list had an $80 / 20$ proportion of related versus unrelated word pairs. In the low relatedness proportion list the additional 120 related word pairs of the high proportion list were replaced by 120 unrelated word pairs, resulting in a 20/80 proportion of related versus unrelated word pairs. The same pseudorandomized sequence was used for the high and the low proportion lists, such that each critical word pair occurs in the same position in both lists. 


\section{Procedure}

The stimuli were generated and controlled by a Miro GD laboratory computer and were centrally presented in a 8 by $2 \mathrm{~cm}$ window on a high-resolution PC monitor which was covered by a black nonreflecting shield. Viewing distance was between 70 and $80 \mathrm{~cm}$, and the stimuli subtended a vertical visual angle of approximately $3^{\circ}$. Primes and targets were presented in uppercase letters. A single trial consisted of the presentation of a prime for $200 \mathrm{~ms}$, followed by a blank screen of $500 \mathrm{~ms}$, followed by the presentation of a target for $200 \mathrm{~ms}$. The interval between trials was $3400 \mathrm{~ms}$.

All subjects were tested individually in a dimly illuminated, sound-attenuating, and electrically shielded booth. At the beginning of the test session subjects were informed that they would see a series of two letter strings. They were told that in some cases the second letter string formed a common word of Dutch, whereas in other cases the second letter string did not exist as a word in the Dutch language. Subjects were randomly assigned to either the lexical decision or the silent reading task.

For the lexical decision task, subjects were required to indicate whether the second letter string was a word by pressing the YES button on a response keyboard with their right index finger for words and the NO button with their left index finger for nonwords. Subjects were asked to respond as quickly as possible, but to avoid errors. No feedback concerning correctness of response was given. Both response times and response codes were stored directly with the aid of the computer. For the silent reading task, subjects were asked to attentively read the stimuli, without attempting to memorize them. Before the test session began, the set of 20 practice stimuli was presented to familiarize the subjects with the procedure.

\section{EEG Recording and Analysis}

EEG activity was recorded using an Electrocap with seven tin scalp electrodes, each referred to the left mastoid. Three electrodes were placed according to the International 10-20 system (Jasper, 1958) at frontal (Fz), central (Cz), and parietal (Pz) midline sites. Symmetrical anterior-temporal electrodes were placed halfway between F7 and T3 (AL) and F8 and T4 (AR) sites, respectively. Symmetrical posterior-temporal electrodes (PL, PR) were placed lateral (by $30 \%$ of the interaural distance) and $12.5 \%$ posterior to the vertex. Vertical eye movements and blinks were monitored via a supra- to suborbital bipolar montage. A right to left canthal bipolar montage was used to monitor for horizontal eye movements.

The EEG and EOG recordings were amplified with Nihon Kohden AB-601G bioelectric amplifiers, using a low-pass filter of $30 \mathrm{~Hz}$ and a time constant of $8 \mathrm{~s}(0.02 \mathrm{~Hz})$. Electrode impedance was at most $3 \mathrm{kOhm}$. The EEG and EOG were digitized online with a sampling frequency of $200 \mathrm{~Hz}$. Sampling started $150 \mathrm{~ms}$ before the prime appeared and continued for $1750 \mathrm{~ms}$.

Trials containing eye blinks (defined as a signal with an amplitude of over $\pm 70 \mu \mathrm{V}$ ) were detected offline and rejected. Prior to analysis, the waveforms were normalized on the basis of the average signal $150 \mathrm{~ms}$ directly preceding the target word (for the prime analyses, the baseline was $150 \mathrm{~ms}$ directly preceding the prime word). Area measures $\left(\mu \mathrm{V}^{2}\right)$ were computed in circumscribed latency windows (see Results for details). These measures were entered into analyses of variance.

\section{RESULTS}

The Lexical Decision Experiment: RT Results

Statistical analyses were performed on the latency data of the 40 critical word target trials in each priming condition. Before the analyses on the la- 


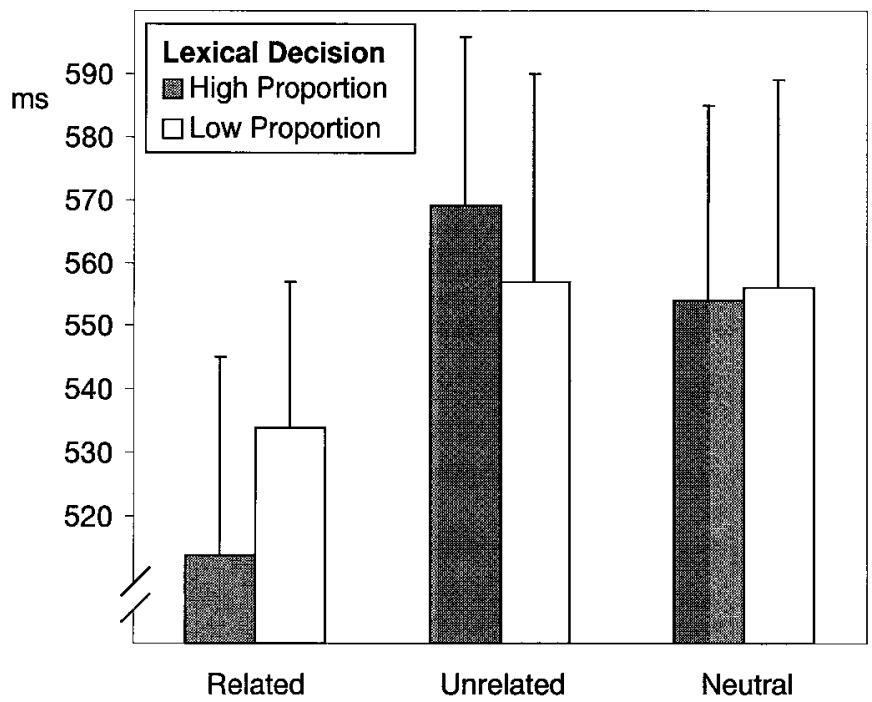

FIG. 1. Lexical decision latencies for the related, unrelated, and neutral conditions for the high and low relatedness proportion lists.

tency data, errors and values above $900 \mathrm{~ms}$ were replaced by the subject's mean latency in the relevant condition. Two subjects, 1 in the High Proportion List and 1 in the Low Proportion List, were excluded from further analyses because of a high percentage of errors and outliers (13\% or more). All analyses (including the analyses on the ERP data) were done on the remaining 28 subjects, 14 in each proportion condition. For these remaining subjects, a total of $4.8 \%$ of errors in the High Proportion List and 3.2\% of errors in the Low Proportion List were replaced by the mean. The results for both proportion conditions are summarized in Fig. 1.

An analysis of variance (ANOVA) with subjects as random factor was performed with Prime Type (Related, Unrelated, Neutral) as the within-subject factor and Relatedness Proportion (High Proportion, Low Proportion) as the between-subjects factor. The Greenhouse-Geisser procedure (cf. Winer, 1971) was applied to all repeated measures with more than $1 d f$. The original degrees of freedom and the adjusted $p$ values are presented in the text.

The overall ANOVA revealed a significant main effect of Prime Type $(F(1,26)=35.45, \mathrm{MSe}=329.02, p<.01)$. In addition a significant Relatedness Proportion by Prime Type interaction was obtained $(F(1,26)=5.94$, MSe $=329.02, p<.05)$. Separate ANOVAs were therefore done for the two proportion conditions.

The ANOVA for the High Proportion List yielded a significant effect of Prime Type $(F(1,13)=25.41, \mathrm{MSe}=450.03, p<.01)$. A posthoc Newman-Keuls test $(p<.05)$ showed a significant facilitation in the related condition relative to both the neutral baseline $(40 \mathrm{~ms})$ and the unrelated con- 
dition $(55 \mathrm{~ms})$. The $15-\mathrm{ms}$ inhibition in the unrelated condition relative to the neutral baseline was marginally significant in a planned comparison ( $p=$ .067).

The ANOVA for the Low Proportion List also yielded a significant effect of Prime Type $(F(1,13)=10.47, \mathrm{MSe}=208.03, p=.01)$. The posthoc Newman-Keuls test again showed a significant facilitation in the related condition relative to both the neutral baseline $(21 \mathrm{~ms})$ and the unrelated condition (22 ms). However, in contrast to the High Proportion List, no inhibition was seen in the unrelated condition relative to the neutral baseline.

In summary, relative to the neutral baseline the RT results showed a pattern of facilitation (related condition) and inhibition (unrelated condition) in the High Proportion List, but only a pattern of facilitation (related condition) in the Low Proportion List. In addition, the overall facilitation of the related condition relative to the unrelated condition was substantially larger in the High Proportion List than in the Low Proportion List (55 ms vs. $22 \mathrm{~ms}$ ).

\section{The Lexical Decision Experiment: ERP Results for the Target Words}

After artifact rejection, statistical analyses were done on the ERP data of the 40 critical target words in each priming condition. All analyses of variance included Prime Type and Electrode Position as the within-subject factors and Relatedness Proportion as the between-subjects factor. Where appropriate, the degrees of freedom and the $p$ values were adapted using the Greenhouse-Geisser procedure (cf. Winer, 1971). The original degrees of freedom and the adjusted $p$ values are reported in the text. Where interactions with the factor Electrode are reported, ANOVAs were performed after $z$ score normalization on the mean amplitudes of each condition separately. This procedure is equivalent to the procedure described by McCarthy and Wood (1985; cf. Rösler, Heil, \& Glowalla, 1993; see also Bush, Hess, \& Wolford, 1993, for a treatment of $z$ score transformations). Figures with ERP data represent average waveforms for the 40 critical items in each priming condition.

Results for the target segment are represented in Fig. 2 for the High Proportion List and in Fig. 3 for the Low Proportion List. The waveforms show a number of distinct endogenous effects. Most prominent among these are modulations at the level of the N400. The N400 effects will be discussed first, before turning to the other ERP effects.

N400 effects. To statistically test possible N400 effects, an ANOVA was performed on the mean amplitudes in the latency range between 300 and $400 \mathrm{~ms}$ after target onset. ${ }^{1}$ In addition to a significant main effect of Prime

\footnotetext{
${ }^{1}$ This relatively restricted time window was chosen after visual inspection of the individual subject waveforms. The morphology of the N400 observed in this experiment is quite sharp, with clear ascending and descending flanks. The chosen analysis window does, therefore, capture the relevant aspects of the N400.
} 

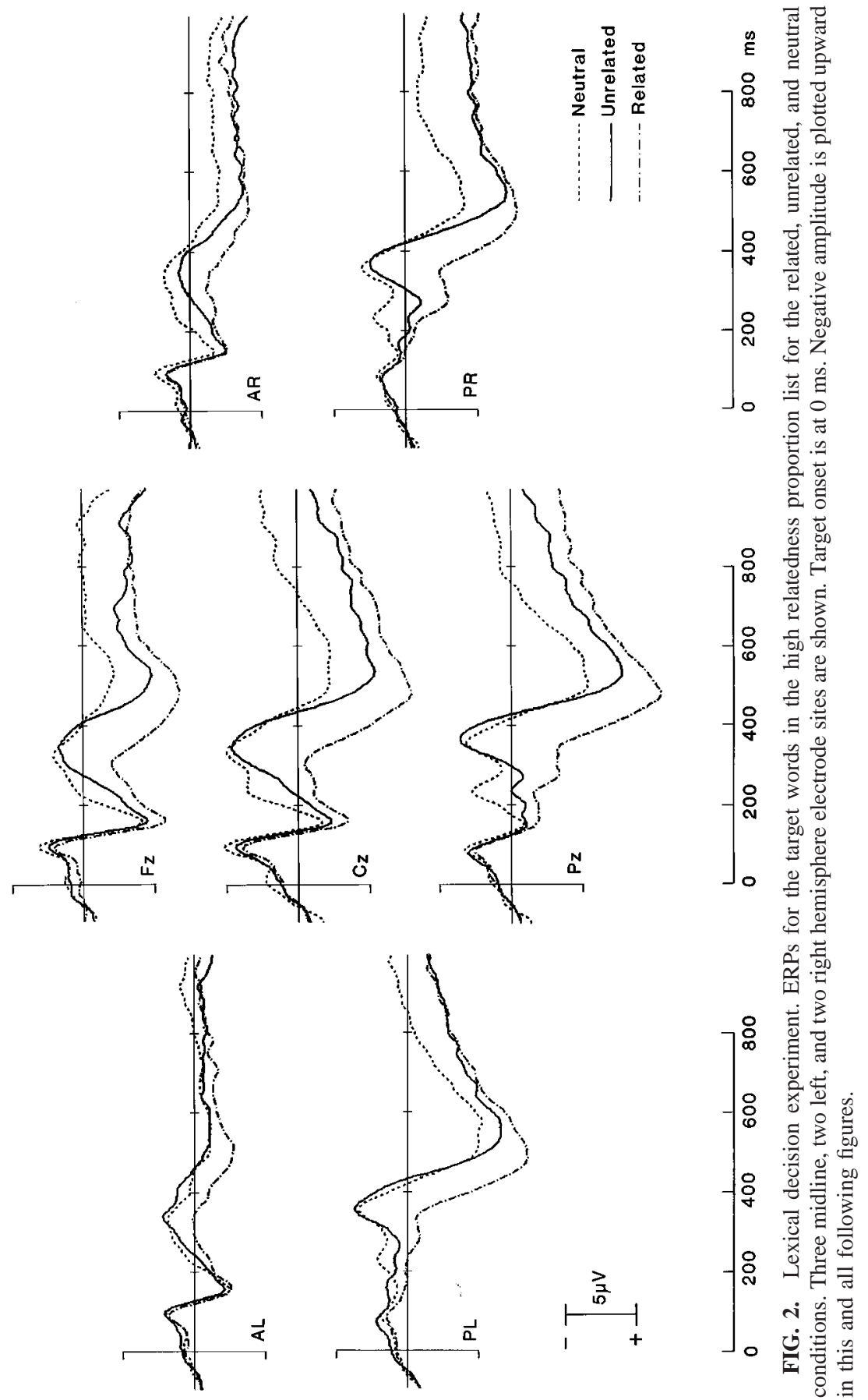

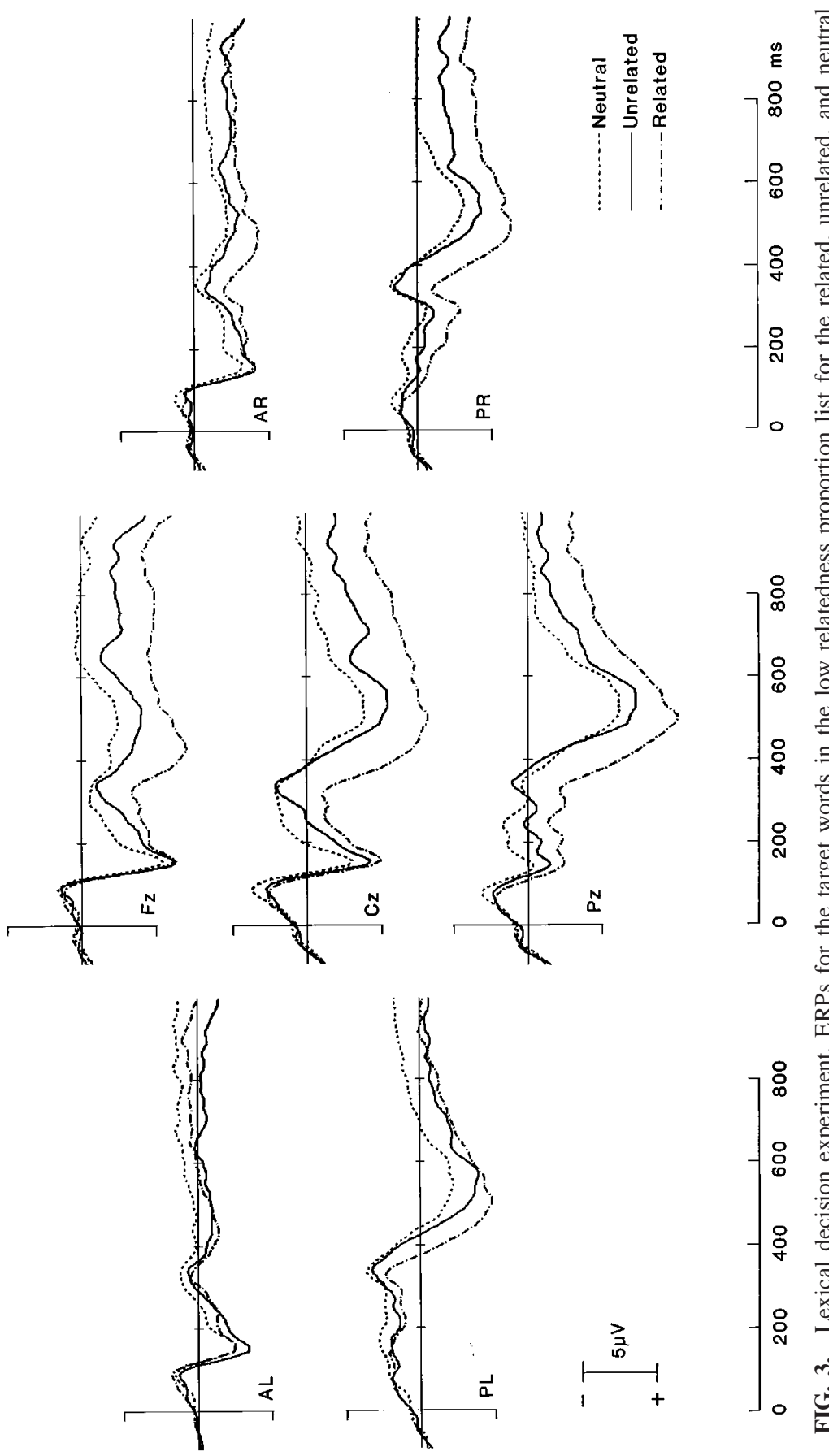

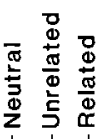

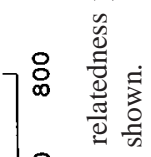

-

$-18.0$

$-\frac{1}{2}$

18

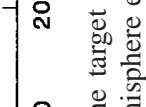

$\checkmark$ ○.

늠

욜

7 品 离

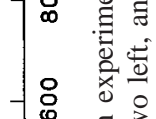

효

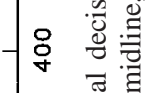

|

引

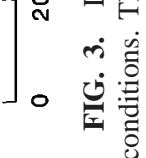




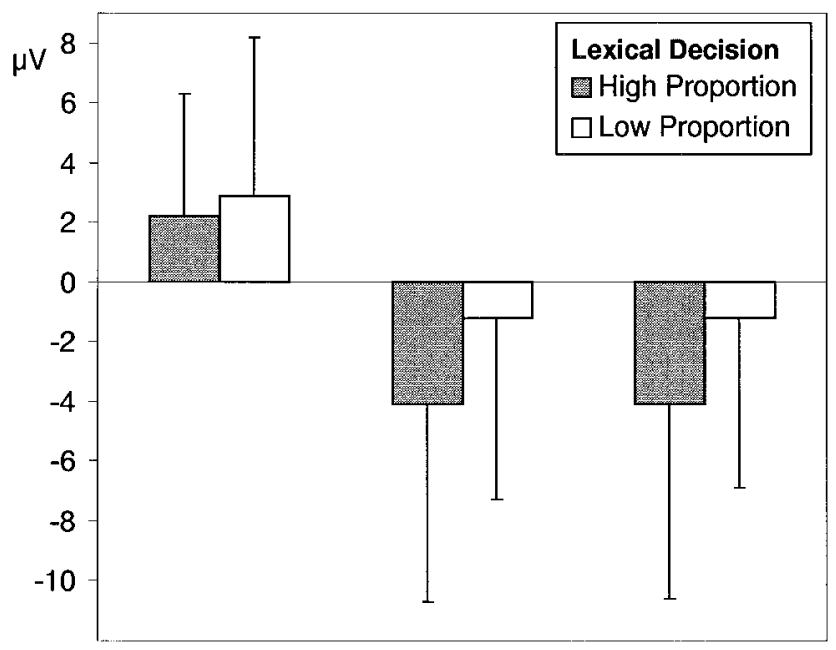

Related

Unrelated

Neutral

FIG. 4. Lexical decision experiment. Mean amplitude at electrode site $\mathrm{Cz}$ of the $\mathrm{N} 400$ in the 300- to 400-ms latency range after stimulus onset for the related, unrelated, and the neutral conditions of the high and low proportion lists.

Type $(F(1,26)=40.62$, MSe $=19.44, p<.01)$, this ANOVA revealed a trend toward a Relatedness Proportion by Prime Type interaction, indicating a larger priming effect in the High Proportion List than the Low Proportion List. To further substantiate this trend, and because in general N400 effects with visual stimulation are dominant over posterior electrode sites, an ANOVA was performed in which the factor Electrode was restricted to three levels, comprising the posterior electrode sites Pz, PL, and PR. This analysis revealed a significant Relatedness Proportion by Prime Type interaction $(F(1,26)=4.45, \mathrm{MSe}=10.17, p<.05)$. Separate analyses were therefore performed for the High Proportion List and the Low Proportion List.

The ANOVA for the High Proportion List (HPL) yielded a significant main effect of Prime Type $(F(1,13)=28.81$, MSe $=22.62, p<.01)$. A Newman-Keuls test $(p<.05)$ revealed a significantly larger N400 amplitude for both the neutral $(-2.18 \mu \mathrm{V})$ and the unrelated $(-2.07 \mu \mathrm{V})$ conditions relative to the related condition $(2.34 \mu \mathrm{V})$. The neutral and the unrelated conditions were not significantly different.

The ANOVA for the Low Proportion List (LPL) similarly revealed a significant main effect of Prime Type $(F(1,13)=12.46$, MSe $=16.26, p$ $<.01)$. The Newman-Keuls test $(p<.05)$ revealed the same pattern of differences as that for the High Proportion List, in that both the neutral $(-0.55 \mu \mathrm{V})$ and the unrelated $(-0.31 \mu \mathrm{V})$ condition differed from the related condition $(2.05 \mu \mathrm{V})$, but not from each other. Figure 4 illustrates the 
pattern of N400 effects for the High and Low Proportion lists, at electrode site $\mathrm{Cz}$.

In addition to the N400 effects, inspection of the waveforms reveals an earlier negative deflection that shows up most clearly at the posterior sites for the neutral condition, as well as a late Slow Wave that also seems to separate the neutral condition from the related and the unrelated conditions. These effects will now be presented in turn.

Early negative effects. The early negative effects, reminiscent of effects on the N200 amplitude, were statistically tested by entering the mean amplitudes in the latency range of 200-300 ms after target onset into an ANOVA. This analysis revealed a significant main effect of Prime Type $(F(1,26)=$ 22.52, $\mathrm{MSe}=14.53, p<.01)$. Neither the main effect of Relatedness Proportion $(F(1,26)=1.72$, MSe $=53.92, p=.20)$, nor the Relatedness Proportion by Prime Type interaction $(F<1)$ approached significance. A posthoc Newman-Keuls test $(p<.05)$ resulted in a significantly more negative mean amplitude for the neutral condition (HPL, $-1.43 \mu \mathrm{V}$; LPL, $-0.15 \mu \mathrm{V}$ ) compared to both the unrelated condition (HPL, $0.21 \mu \mathrm{V}$; LPL, $1.02 \mu \mathrm{V}$ ) and the related condition (HPL, $1.64 \mu \mathrm{V}$; LPL, $1.94 \mu \mathrm{V}$ ). Moreover, the difference between the related and the unrelated conditions was also significant.

Slow Wave effects. To test the Slow Wave effects, overall mean amplitudes in the area between 600 and $900 \mathrm{~ms}$ posttarget were entered into an ANOVA. The overall ANOVA yielded a significant main effect of Prime Type $(F(1$, $26)=31.80, \mathrm{MSe}=14.92, p<.01)$. Neither a significant main effect of Relatedness Proportion $(F<1)$, nor a significant interaction between Relatedness Proportion and Prime Type $(F<1)$ was obtained. A posthoc Newman-Keuls test $(p<.05)$ showed that the neutral condition was more negative (HPL, $0.88 \mu \mathrm{V}$; LPL, $0.35 \mu \mathrm{V}$ ) than both the related (HPL, $3.92 \mu \mathrm{V}$; LPL, $3.39 \mu \mathrm{V}$ ) and the unrelated (HPL, $3.38 \mu \mathrm{V}$; LPL, $2.03 \mu \mathrm{V}$ ) conditions. The unrelated condition was more negative than the related condition.

Interactions with the factor Electrode. No significant three-way interactions with Prime Type and Relatedness Proportion were observed. Significant two-way interactions with Prime Type were obtained for the N200, N400, and Slow Wave components. These interactions reflect the distribution of the experimental effects over the scalp. The condition effects were minimal at lateral and frontal sites and maximally different at centroparietal sites. This was in accordance with the standard topography of the components analyzed - all showing a centroparietal maximum — and has little bearing on the cognitive-functional interpretation of the condition effects. ${ }^{2}$

\footnotetext{
${ }^{2}$ Visual inspection of the waveforms indicates a somewhat larger N400 effect over the right (mainly posterior) electrode sites, compared to the left sites, in particular for the low relatedness proportion list. This topographic pattern is often seen with visual stimulation (e.g., Holcomb, 1988; Holcomb \& Neville, 1990; Kutas \& Van Petten, 1988, 1994). To investigate whether the effects of the relatedness proportion manipulation interacted with a possible right-
} 
Summary. In summary, the main finding of this ERP lexical decision experiment was that the overall N400 priming effect as indicated by the difference between the related and the unrelated conditions was larger in the High Proportion List $(4.41 \mu \mathrm{V})$ than in the Low Proportion List $(2.36 \mu \mathrm{V})$. This resulted in the only significant Relatedness Proportion by Prime Type interaction for the ERP data of this experiment. Relatedness proportion thus has an effect on the amplitude of the N400. In addition, early negative effects and late Slow Wave effects were obtained, but these did not vary as a function of relatedness proportion.

\section{Discussion of the Target Effects}

$R T$ and N400 priming effects. The RT results showed the expected effect of the relatedness proportion manipulation (cf. Neely, 1991). That is, inhibition was obtained for the unrelated condition relative to the neutral baseline in the High Proportion List, but not in the Low Proportion List. In addition, the overall semantic priming effect was larger in the High Proportion List than in the Low Proportion List. The relatedness proportion effect is attributed to expectancy-induced priming. As was mentioned in the Introduction, this form of priming is thought to emerge because subjects use the prime to generate an expectancy set that contains potential targets related to that particular prime. The relatedness proportion effect results from the increase in the probability that subjects will use the prime to generate an expectancy set as the relatedness proportion increases (Becker, 1980). The pattern of RTs obtained here indicates that the subjects did indeed generate expectancy sets for the High Proportion List and refrained from doing so in the Low Proportion List.

The statistical analysis of the ERP data revealed that only for the N400 a significant relatedness proportion by Prime Type interaction was obtained. This indicates that the size of the N400 effect is influenced by the proportion of related word pairs. Earlier research (Brown \& Hagoort, 1993) has shown that the amplitude of the N400 is not sensitive to the automatic spreading of activation between related nodes in the semantic lexicon. The results of the present experiment, then, suggest that the amplitude of the N400 is modulated by expectancy.

However, in contrast to the pattern of RT results in the High Proportion List, the amplitude of the N400 for the unrelated condition did not differ from that in the neutral condition. That is, the inhibition in the unrelated condition, as revealed by longer RTs compared to the neutral baseline, does

left topographic difference, we performed two separate ANOVAs with the factors Relatedness Proportion, Prime Type, and Hemisphere. One ANOVA contrasted right and left sides of the head, collapsing over anterior and posterior electrode sites. The other ANOVA focused only on the posterior right and left sites. Neither ANOVA revealed any interaction of Relatedness Proportion and Prime Type with Hemisphere. 
not translate into a larger $\mathrm{N} 400$ amplitude in the unrelated condition relative to the neutral condition. This result is in line with relatedness proportion effects reported by Holcomb (1988), but contrasts with the work of Koyama, Nageishi, and Shimokochi (1992). However, the two experiments reported by Koyama et al. differ in important respects from those of Holcomb (1988) and of the present study, making a direct comparison difficult. ${ }^{3}$ To date, the Holcomb (1988) study and the work reported here present the most consistent picture of relatedness proportion effects and the N400 in a lexical decision task. $^{4}$

A possible explanation for the difference between the RT and ERP results is that the amplitude of the N400 is especially sensitive to the initial search through the expectancy set, with a reduction in amplitude if the target is a member of the set. The inhibition might be more tightly linked to the taskrelated decision process, requiring extra processing of the target features if these do not match candidates in the expectancy set. This, then, would show up in longer RTs, but not in the amplitude of the N400.

Although the amplitude of the N400 seems to reflect semantic expectancy, this cannot be the only priming mechanism that modulates the N400 amplitude. Assuming that expectancy did not contribute in any substantial way to the priming effects in the Low Proportion List, the reduction of the N400 amplitude for the related targets in this list indicates that in this case another priming mechanism must be responsible for the N400 effect. This

\footnotetext{
${ }^{3}$ Koyama et al. found an increased N400 in a high relatedness proportion list for the unrelated condition compared to the related and the neutral conditions, but the latter two conditions did not differ. In these experiments the same word prime was repeatedly presented both within and across priming conditions, using a stimulus onset asynchrony (SOA) of $1500 \mathrm{~ms}$, which is longer than the SOA used in Holcomb's (1988) and in the present study. The prime repetition across all three priming conditions, in combination with the long SOA, could have led to processing strategies that were absent in Holcomb's (1988) and in our experiments. In particular the occurrence of one and the same prime with either related or unrelated targets is a factor that could contribute to the saliency for the subjects of the relationship between primes and targets. This possibility is enforced by the fact that in the experiment using a low relatedness proportion list, Koyama et al. did not observe any effects at the level of the N400, not even the standard difference between the related and unrelated conditions.

${ }^{4}$ There are, however, some differences, of lesser and greater importance, between Holcomb's study and the present one. First, Holcomb did not use a neutral prime stimulus but a blank screen and so cannot demonstrate as we are able to that the relatedness proportion manipulation brings about the predicted RT pattern of facilitation and inhibition. In fact, Holcomb did not observe an RT difference between his neutral and unrelated conditions. Second, Holcomb attempted to influence the subjects' processing of the prime by means of an explicit instruction to attend or not attend to the meaning of the prime. This instructional manipulation introduces a degree of uncertainty about the subjects' behavior that we have avoided in our study. Finally, and in the context of our paper most importantly, Holcomb did not include a comparison with the silent reading task (he had no reason to, given the purpose of the research he was engaged in). This precludes any further analysis of the possibly task-induced nature of the relatedness proportion effect, which is of course a major aspect of the work we are presenting here.
} 
priming mechanism most likely is semantic matching (cf. Neely, 1991; also called postlexical coherence checking, De Groot, 1984). On the basis of lexical-semantic information, the semantic matching mechanism attempts to establish a meaningful (i.e., semantic) link between the prime and the target. If this matching process is successful, a coherent (i.e., integrated) representation results. Semantic matching is not considered an automatic, reflex-like process. It can be argued, however, that it is a mandatory process (cf. Fodor, 1983) and as such is a standard part of the task performance during lexical decision. The stronger the semantic overlap between prime and target, the better the match, and the more reduced the amplitude of the N400 will be. This matching process shares characteristics with the integration of word meanings into an overall meaning representation of a sentence.

Early negative effects. The separation at the level of the N200 of the neutral and unrelated conditions from the related condition can be seen as an early indication of the upcoming N400 effect. The significant difference between the neutral and the unrelated condition, however, is not linked to the N400. The explanation here is that the neutral-unrelated difference is reflecting that subjects have aborted any attempt to establish a link between the prime and the target. By hypothesis, the reason this aborted linkage effect should at all come about is because as a default rule, subjects will always attempt to establish a relation (of whatever nature, but a semantic relation is presumably a standard attempt) between the prime and the target. This suggests that the effect arises from stimulus classification operations. Specifically, the data indicate that the subjects separately classified the blancoword pairs. These pairs represent a separate class for the subjects, both on the basis of their low probability of occurrence within the entire stimulus list and on the basis of the inability to achieve a match, due to the essentially meaningless, and hence non-wordlike, nature of the neutral prime. So, the stimulus classification of the neutral prime leads to a specific effect for the neutral condition, manifesting itself at the level of the N200 as an enhanced negative amplitude. Although this interpretation has to remain tentative at this point, there is ample evidence in the ERP literature that stimulus classification effects are reflected in the N200 (see for reviews: Pritchard, Shappell, \& Brandt, 1991; Ritter, Ford, Gaillard, Harter, Kutas, Näätänen, Polich, Renault, \& Rohrbaugh, 1984).

The present data also contribute to the discussion in the psychophysiological literature on the separation of the N200 and the N400. It has at times been claimed that the N400 is in fact a delayed N200 (cf. Polich, 1985a; see Pritchard et al., 1991, for an extensive review and discussion of the N200/ N400 debate). The occurrence of both an N200 and an N400 in our data, together with the fact that only the N400 is modulated by relatedness proportion, strongly suggests that we are dealing with two separate components here. 
Slow Wave effects. Continued and differential processing of the stimuli beyond the time window of the N400 is reflected in the significant Slow Wave effects in the 600- to 900 -ms range postonset. Here no effect of the relatedness proportion manipulation was found, but the waveform for the neutral condition is more negative going than that for the unrelated condition, which, in turn, is more negative than the waveform for the related condition. These negative Slow Wave effects can be interpreted as reflecting the differential processing load of the three conditions with respect to the extent to which the subjects can establish any kind of link between the prime and the target. The assumption here is that irrespective of the specific task demands, subjects always attempt to construct an integrated representation of the word pair. The link that is established can be at any level of representation, be it linguistic or nonlinguistic, and, hence, involves a broader process than semantic matching, that is restricted to linguistic information. If semantic matching is successful, no further attempts at finding a relation between the prime and the target are necessary. However, if semantic matching does not establish a link, which will at least initially be the case for the unrelated pairs and certainly for the targets preceded by a neutral prime, this does not necessarily mean that all attempts at linking the prime and target are abandoned. Subjects can continue to try to find a relation of whatever nature, thereby appealing to essentially any kind of knowledge.

With respect to the Slow Wave effects, the pattern of results is quite clear. In the case of a semantic relationship between the prime and the target, a link is readily obtained and, hence, the processing load is low. This is reflected in the Slow Wave for the related condition. When the prime and the target are semantically unrelated, a link is more difficult, although not necessarily impossible, given enough time (e.g., doctor and fatigue are pragmatically related, since doctors often work long shifts). This difficulty is associated with a higher processing load, which emerges as an increased negative Slow Wave for the unrelated condition in comparison with the related condition. The neutral condition, finally, presents the highest processing load in terms of a linkage process. Here the subject has essentially almost no features (physical or semantic) available with which to establish a link. This interpretation of the negative Slow Wave effects is in accordance with a number of experiments reporting differential Slow Waves as a function of the amount of conceptual processing (see Ruchkin, Johnson, Mahaffey, \& Sutton, 1988, for a discussion and functional categorization of Slow Waves).

\section{The Silent Reading Experiment: ERP Results for the Target Words}

Whether the expectancy-based priming mechanism is part of the set of processes normally involved in language processing or whether it is a product of the task requirements in RT priming studies cannot be answered on the 
basis of the current priming literature. To establish priming effects by using RT methods, it is necessary to collect responses to the targets in tasks such as lexical decision and pronunciation. Given these task requirements, if the proportion of related pairs is relatively high, generating an expectancy set on the basis of the prime information is a good strategy for meeting the demands of the experiment. It might be the case, however, that under the same stimulus conditions the expectancy mechanism is not invoked by subjects if the task requirements do not reinforce such a strategy. Such a situation obtains when subjects are asked to do only what they are used to doing in visual language processing, namely, to read the words. An advantage of the ERP method is that in this reading-only task environment, reliable ERP effects can still be obtained. To discover, then, whether expectancy-based priming also occurs when subjects are not required to do anything other than reading, the same experiment was run in terms of stimuli and conditions as the lexical decision experiment, but without any other task demands over and above reading the words for understanding.

Results for the High Proportion List and the Low Proportion List are represented in Figs. 5 and 6, respectively. All analyses in Experiment 2 were done in exactly the same way as those in Experiment 1.

N400 effects. Inspection of the waveforms indicates that N400 effects emerged slightly later following target onset than in the lexical decision experiment. An ANOVA was performed on the mean amplitudes in the latency range between 350 and $450 \mathrm{~ms}$ after target onset. This analysis yielded a significant effect of Prime Type $(F(1,26)=25.19, \mathrm{MSe}=19.38, p<.01)$. However, the Relatedness Proportion by Prime Type interaction did not approach significance $(F(1,26)=1.39, \mathrm{MSe}=19.38, p>.20)$, indicating the absence of an effect of Relatedness Proportion on the size of the N400 priming effects. This was substantiated in an analysis on only the posterior electrode sites Pz, PL, and PR (the same analysis as was performed on the lexical decision data), which again did not result in a significant interaction of Relatedness Proportion by Prime Type $(F<1)$. The main effect of Relatedness Proportion was not significant either $(F(1,26)=1.19$, MSe $=43.60$, $p>.25)$. To further substantiate this nonsignificance, additional posthoc analyses were performed on the Relatedness Proportion effect for each individual electrode site. These analyses clearly confirm the results of the overall ANOVA. In an ANOVA on all three conditions and both relatedness proportions, none of the individual electrode sites show anything approaching a significant interaction of Prime Type with Relatedness Proportion. In an ANOVA contrasting the related and unrelated conditions, five of the seven electrode sites show no effect (PR and AR do show effects). In an ANOVA on the related and neutral conditions, no significant interactions are obtained for any of the electrode sites.

A posthoc Newman-Keuls test revealed that the neutral condition was 

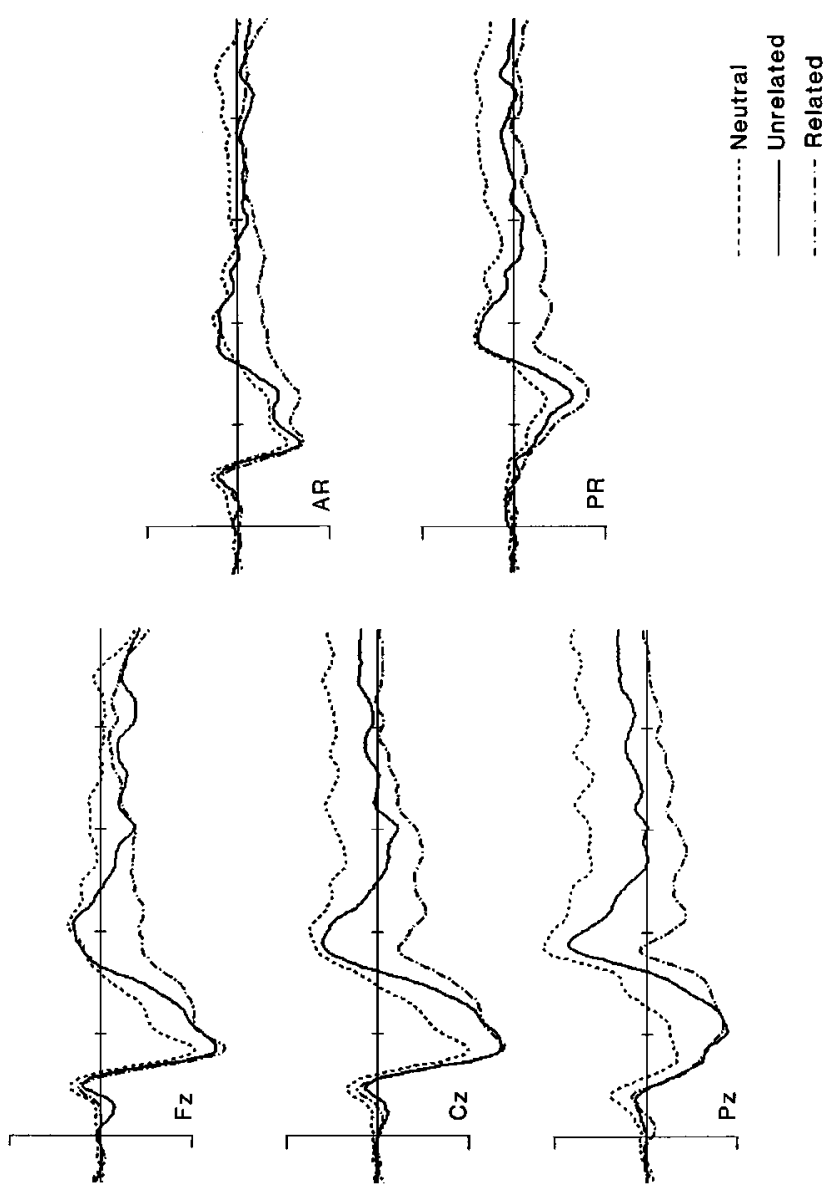

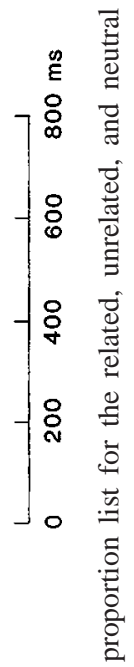

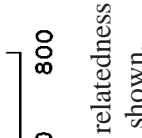

$-180$

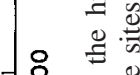

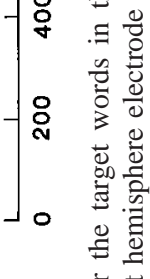

훈 흠

के :
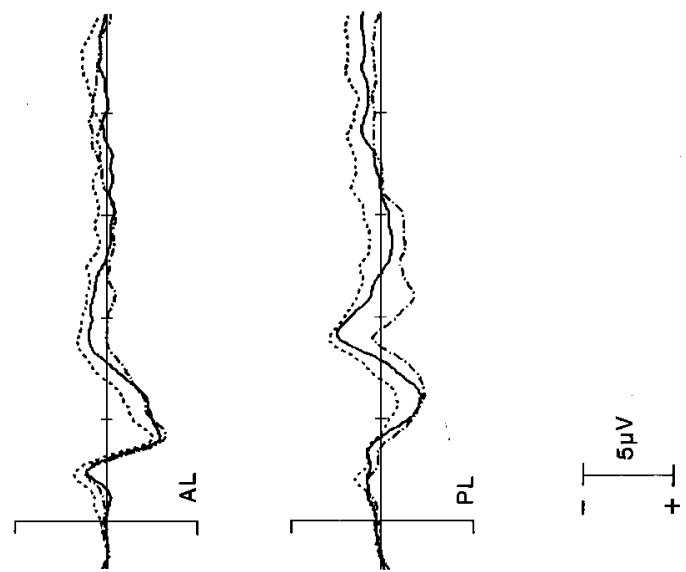

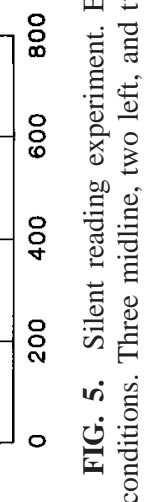



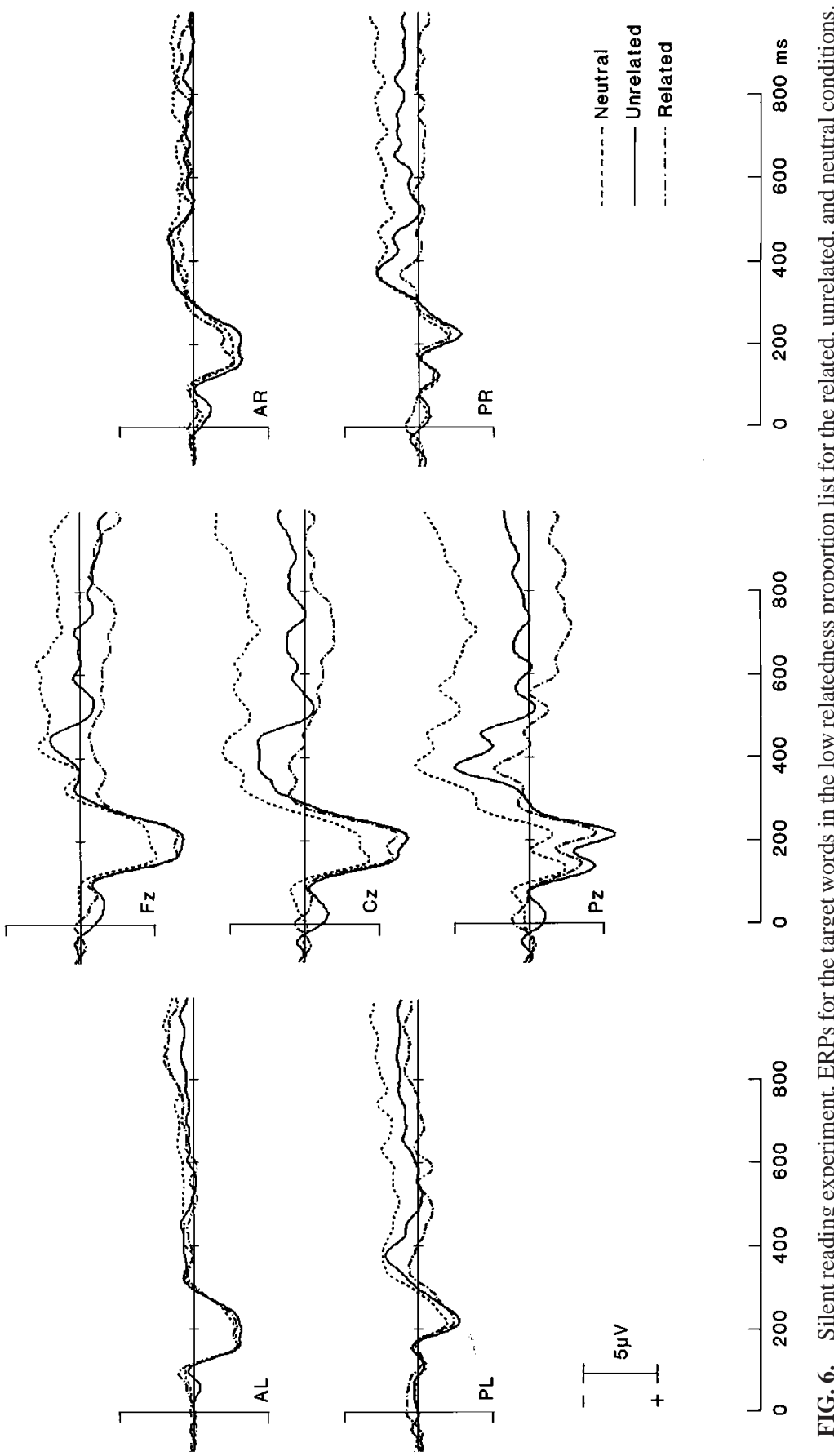

可

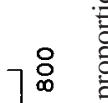

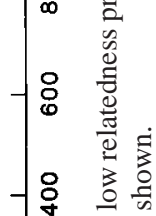

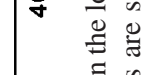

- 웅

1
0
$0 \quad 00$
0
0

宓苍

$\stackrel{0}{\Xi}$

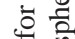

$\circ \stackrel{\text { 虫 }}{\circ}$

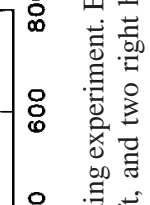

-18 守 䒿

-8 运

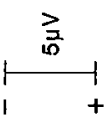

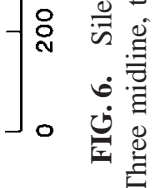




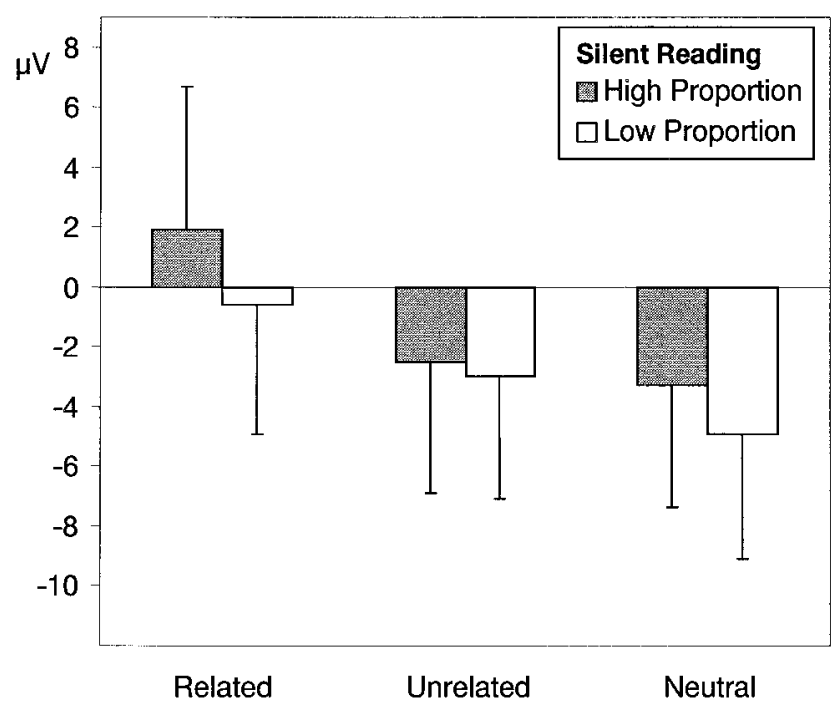

FIG. 7. Silent reading experiment. Mean amplitude at electrode site $\mathrm{Cz}$ of the $\mathrm{N} 400$ in the 350- to 450-ms latency range after stimulus onset for the related, unrelated, and neutral conditions of the high and low proportion lists.

significantly more negative (HPL, $-2.24 \mu \mathrm{V} ; \mathrm{LPL},-2.72 \mu \mathrm{V}$ ) than both the unrelated condition (HPL, $-1.68 \mu \mathrm{V} ; \mathrm{LPL},-1.87 \mu \mathrm{V})^{5}$ and the related condition (HPL, $1.33 \mu \mathrm{V}$; LPL, $-0.26 \mu \mathrm{V}$ ). Moreover, the N400 amplitude in the unrelated condition was more negative than in the related condition. Figure 7 illustrates the pattern of N400 effects for both proportion lists, at electrode site $\mathrm{Cz}$.

${ }^{5}$ This difference at the level of the N400 between the neutral and the unrelated conditions contrasts with the results of the lexical decision experiment and is an unexpected finding. We do not, however, attach any functional significance to this effect, because its origin most likely lies in a baseline problem for the neutral condition. Inspection of the waveforms indicatesin particular for the low proportion condition - that the waveform for the neutral condition deviates very early from the baseline, in some cases well before the $\mathrm{N} 1$ component. The reason for this baseline problem is unknown. To investigate whether a baseline shift underlies the effect for the neutral condition, we reanalyzed the data, after first normalizing within the 75to 125-ms window following target onset. This normalization aligns the neutral waveform with the related and unrelated waveforms, at the level of the N1. An ANOVA on the mean amplitudes of the renormalized data in the latency range between 375 and $475 \mathrm{~ms}$ after target onset yielded a significant effect of Prime Type. Once again, the Relatedness Proportion by Prime Type interaction did not approach significance, nor did a main effect of Relatedness Proportion obtain. Posthoc Newman-Keuls tests showed that the neutral and the unrelated conditions were more negative than the related condition. Critically, however, after adjusting the neutral waveform with respect to its early deviation from the baseline, no significant difference was obtained between the neutral and the unrelated conditions. It seems, therefore, that the difference observed in the original analysis should indeed be attributed to a baseline problem for the neutral condition. 
Early negative effects. Although the morphology is not as distinct as that in the lexical decision experiment, there are indications of early separations for the different conditions. These possible early effects were assessed by entering the mean amplitudes between 200 and $300 \mathrm{~ms}$ posttarget into an ANOVA. This analysis yielded a significant effect of Prime Type $(F(1$, $26)=10.46, \mathrm{MSe}=16.62, p<.01$ ), but not of Relatedness Proportion $(F<1)$. No significant Relatedness Proportion by Prime Type interaction was obtained $(F(1,26)=1.63, \mathrm{MSe}=16.62, p>.25)$. As in Experiment 1 , a posthoc Newman-Keuls test $(p<.05)$ showed that the neutral condition was more negative (HPL, $1.16 \mu \mathrm{V}$; LPL, $1.27 \mu \mathrm{V}$ ) than both the unrelated condition (HPL, $2.96 \mu \mathrm{V}$; LPL, $2.64 \mu \mathrm{V}$ ), and the related condition (HPL, $3.56 \mu \mathrm{V}$; LPL, $2.22 \mu \mathrm{V}$ ), but the latter two conditions did not differ from each other.

Slow Wave effects. An analysis of the Slow Wave effects was performed on the mean amplitudes in the area between 600 and $900 \mathrm{~ms}$ posttarget. The ANOVA yielded a significant effect of Prime Type $(F(1,26)=11.99$, MSe $=26.55, p<.01)$. Neither the effect of Relatedness Proportion $(F<$ $1)$, nor the Relatedness Proportion by Prime Type interaction $(F<1)$ was significant. A posthoc Newman-Keuls test $(p<.05)$ resulted in a significantly larger negativity for the neutral condition (HPL, $-1.48 \mu \mathrm{V}$; LPL, $-2.48 \mu \mathrm{V}$ ), relative to both the unrelated (HPL, $0.06 \mu \mathrm{V}$; LPL, $-0.52 \mu \mathrm{V}$ ) and the related (HPL, $0.44 \mu \mathrm{V}$; LPL, $0.55 \mu \mathrm{V}$ ) conditions. The unrelated condition and the related condition did not differ.

Interactions with the factor Electrode. The factor Electrode shows the same pattern of effects as in the lexical decision experiment. No three-way interactions with Prime Type and Relatedness Proportion are seen. Significant two-way interactions with Prime Type were obtained for the early negative, N400, and Slow Wave components. Here again, the interactions with Electrode are a straightforward reflection of the distribution of the experimental effects over the scalp, originating from the centroparietal topography of the analyzed components. No significant three-way interactions were found with Hemisphere.

\section{Discussion of the ERP Target Effects}

In contrast to the lexical decision task, the silent reading task did not result in a differential N400 priming effect between the High Proportion List and the Low Proportion List. Furthermore, as in the lexical decision experiment, the neutral condition showed a larger early negativity and a larger negative Slow Wave in comparison with the related and the unrelated conditions. These effects were likewise not affected by the relatedness proportion manipulation.

The early effect for the neutral condition mirrors the effect found in the lexical decision experiment. This can be taken as support for the claim that 
irrespective of the specific task environment, in the context of a lexical priming paradigm subjects engage in a stimulus classification process. In the present experiments, using a neutral prime (i.e., blanco), the classification leads to an aborted linkage process for the neutral prime-target pairs.

As was argued for the lexical decision experiment, the Slow Wave effects can be interpreted as reflecting differential processing load, connected to continued attempts by the subjects to establish a link — of whatever naturebetween the members of each word pair. The nonsignificant difference between the related and unrelated conditions, which contrasts with the results of the lexical decision experiment, might be reflecting the fact that subjects are less actively engaged in a linkage process when only silently reading stimuli. It seems reasonable to assume that compared to the silent reading situation, the lexical decision task will elicit more attempts at linking, and hence a higher processing load, since it is only in the latter task that a successfully established link can directly aid the task-related decision process.

Although no relatedness proportion effect was found, it is of critical importance to note that a semantic priming effect did obtain in the silent reading task: The N400s to the targets in both the neutral and the unrelated conditions are significantly larger than the N400 elicited by the targets in the related condition. This classical N400 priming effect demonstrates that the subjects accessed the meaning of the primes and the targets and attempted to relate these meanings together.

\section{ERP Effects to the Primes in Both Experiments}

Waveforms for the prime segment $(0-700 \mathrm{~ms})$ are represented in Fig. 8. Electrode site $\mathrm{Cz}$ is shown for both proportion lists and for both experiments. Only one electrode site is shown in order to reduce the visual complexity of the figure, but this site is representative of the differential effect for the neutral condition compared to the related and unrelated conditions.

Inspection of Fig. 8 reveals a clear difference between the waveform for the neutral prime (i.e., the word blanco) and the waveforms for the word primes in the related and the unrelated conditions. The waveform for the neutral prime shows a positive deflection relative to the waveforms for the other two conditions. The positive deflection starts to become particularly salient at around $300 \mathrm{~ms}$. This positivity was tested in an analysis of variance on the mean amplitude in the area between 300 and $500 \mathrm{~ms}$ after prime onset, for the lexical decision and silent reading experiment separately.

ERP prime effects in the lexical decision experiment. The overall ANOVA yielded a significant main effect of Prime Type $(F(1,26)=29.93$, MSe $=$ 13.04, $p<.01)$. Neither the main effect of Relatedness Proportion $(F(1$, $26)=1.15, \mathrm{MSe}=45.64, p>.30$ ), nor the Relatedness Proportion by 
LEXICAL DECISION

High

Proportion

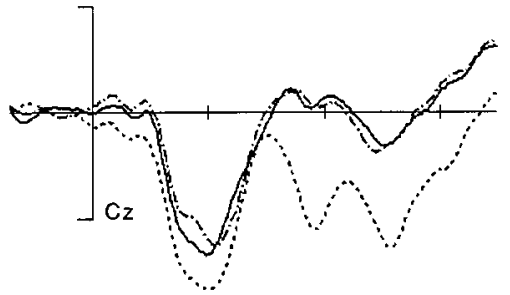

Low

Proportion

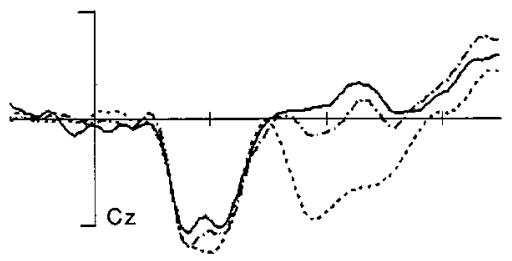

SILENT READING
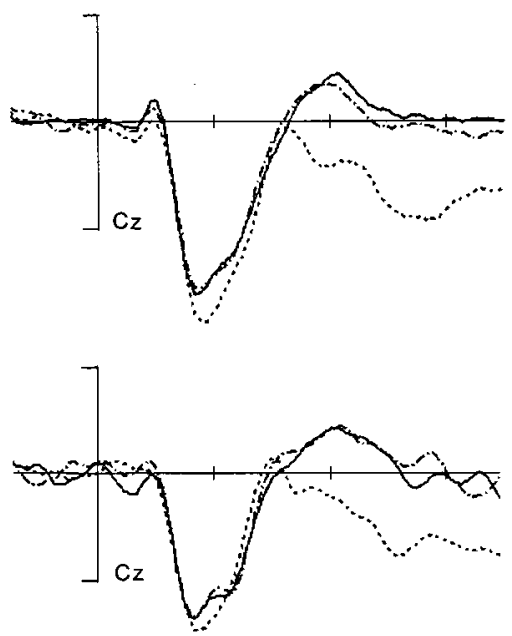

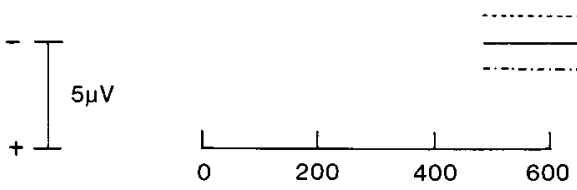

Neutral ('blanco')

Unrelated

Related

FIG. 8. ERPs to the prime words in both experiments, for both relatedness proportion lists, for the related, unrelated, and neutral conditions. Electrode site $\mathrm{Cz}$ is shown.

Prime Type interaction $(F(1,26)=1.43, \mathrm{MSe}=13.04, p>.25)$ approached significance. A posthoc Newman-Keuls test $(p<.05)$ revealed that the neutral condition was more positive (HPL, $3.92 \mu \mathrm{V}$; LPL, $2.78 \mu \mathrm{V}$ ) than both the related condition (HPL, $1.09 \mu \mathrm{V}$; LPL, $1.16 \mu \mathrm{V}$ ) and the unrelated condition (HPL, $1.10 \mu \mathrm{V}$; LPL, $0.37 \mu \mathrm{V}$ ). The latter two conditions did not differ.

In the High Proportion List the positivity is followed by a (more frontal) negative deflection, but carries through as an overall sustained positive shift into the negative shift preceding the target. This negative shift can be classified as a contingent negative variation (CNV), reflecting preparatory activity in anticipation of the upcoming target (cf. Rösler, Sutton, Johnson, Mulder, Fabiani, Plooij-van Gorsel, \& Roth, 1986). In the Low Proportion List the positivity results in a slightly smaller, but again sustained, shift in the CNV region.

None of the analyses with the factor Electrode show a significant threeway interaction with Prime Type and Relatedness Proportion. That is, the relatedness proportion manipulation does not elicit different scalp topographies for the analyzed components. The only significant two-way interaction is with Prime Type and only for the region of the Late Positivity. This interaction can be entirely explained in terms of the centroparietal distribution of 
the Late Positivity for the neutral condition: This condition differs greatly at mainly the central and parietal electrode sites from the related and unrelated conditions, which do not differ among themselves at any site.

ERP prime effects in the silent reading experiment. The CNV that was observed under lexical decision is not present under silent reading. As in the lexical decision experiment, a clear positive shift is seen for the neutral primes, again starting slightly later than $300 \mathrm{~ms}$ after stimulus onset. This positive shift is sustained into the time window of the upcoming target and is largest at posterior sites.

The absence of a CNV preceding the target in all of the experimental conditions in the silent reading experiment, in combination with the presence of a CNV in all of the conditions of the lexical decision experiment, might be reflecting differences in the task demands of the two experiments, in particular the fact that subjects in the lexical decision experiment are operating under time pressure, having been instructed to respond as rapidly as possible to each target. An alternative explanation, however, lies in the presence of the preparation for a motor response in the lexical decision experiment and in the absence of any motor activity in the silent reading experiment. Preparatory motor processes emerge in the Readiness Potential (cf. Brunia, 1988, 1993), which manifests itself as a slow negative wave in the time window immediately preceding movement.

The ANOVA on the positivity resulted in a significant main effect for Prime Type $(F(1,26)=7.33$, MSe $=15.19, p<.05)$. Neither the main effect of Relatedness Proportion, nor the Relatedness Proportion by Prime Type interaction approached significance (both $F \mathrm{~s}<1$ ). A posthoc Newman-Keuls test $(p<.05)$ revealed that the neutral condition was more positive (HPL, $1.67 \mu \mathrm{V}$; LPL, $1.22 \mu \mathrm{V}$ ) than both the related condition (HPL, $0.28 \mu \mathrm{V}$; LPL, $-0.01 \mu \mathrm{V}$ ) and the unrelated condition (HPL, $0.41 \mu \mathrm{V}$; LPL, $-0.12 \mu \mathrm{V})$. The latter two conditions did not differ.

No three-way interactions with the factor Electrode were observed. The only significant two-way interaction is with Prime Type and Electrode and is restricted to the Late Positivity. This topographical effect reflects the posterior distribution of the effect for the neutral condition.

\section{Summary of the ERP Prime Effects in Both Experiments}

In summary, the results for the prime segment in both experiments do not show a difference between the primes in the related and unrelated conditions. This comes as no surprise given that the word primes in these conditions are closely matched items. For both the high and low proportion lists, however, the neutral condition is clearly different from the other two conditions, showing a substantial late positive effect. It is important to note that these positivities are not modulated by relatedness proportion. 


\section{GENERAL DISCUSSION}

\section{On "Neutral" Primes}

The significant positive deflection in both experiments, and in both relatedness proportion lists, for the primes in the neutral condition compared to the related and unrelated conditions can be explained as one of two effects or as a combination of the two.

A first explanation of the positivity is to interpret it as a repetition effect. In contrast to the related and unrelated conditions, in the neutral condition the same prime (i.e., blanco) is repeatedly presented. It is by now firmly established that compared to control items, ERPs to repeated words are characterized by a topographically widespread and temporally sustained positive going shift (e.g., Besson \& Kutas, 1993; Rugg, 1985, 1987; Rugg \& Doyle, 1992; Van Petten, Kutas, Kluender, Mitchiner, \& McIsaac, 1991). The positive shift that we observe for the neutral primes can be interpreted as an effect of the repeated activation of a representation in lexical memory, perhaps in combination with the repeated activation of the episodic trace of that event (cf. Rugg, 1987).

A second explanation of the positivity is to interpret it as an effect of the probability of occurrence of the blanco stimulus. It is well established that task-relevant attended stimuli that have a relatively low probability of occurrence elicit a so-called P300 component in the ERP waveform (cf. Fabiani, Gratton, Karis, \& Donchin, 1987). Within the entire list of stimuli of the present experiment, the neutral primes are low probability events. That is, assuming that the subjects classify the neutral prime as a different kind of stimulus than the words and nonwords, then within the entire list of stimuli the neutral prime can be seen as an "oddball'" stimulus. Hence, the positive effect could be interpreted as a P300 oddball effect. What this would mean in the context of the current experiment is that subjects are sensitive to the fact that the neutral prime stimuli are low probability events relative to all the meaningful word primes they are presented with. Part of this sensitivity possibly stems from the fact that the neutral stimulus blanco is essentially meaningless, in clear contrast with the meaningfulness of all the other primes.

Within the context of the two experiments reported here, it remains unresolved whether the positivity should best be characterized as a repetition or as an oddball effect. The experiment was not intended to investigate this distinction, and the design does not allow separating the two. An important point to reiterate here is that the positive shift is not in any way affected by the relatedness proportion manipulation, which is the main variable under investigation in the present series of experiments.

Turning to the issue of the appropriateness of the blanco prime as a neutral stimulus, the data show that the blanco prime elicits differential processing compared to the word primes used in the related and unrelated conditions. 
This effect obtains irrespective of whether subjects are engaged in a lexical decision task or are only reading the stimuli. Note, however, that using this particular neutral prime, the standard RT relatedness proportion effect is replicated, and in this respect our results are consistent with the RT literature. However, what the ERP results indicate is that despite the label of "neutral prime," the blanco stimulus stands apart from other word primes.

It cannot be concluded from the ERP effect for the blanco prime that a string of nonletter symbols is therefore a more adequate neutral stimulus. In this respect the present data do not resolve the discussion on word versus nonword neutral primes. However, the data do indicate that perhaps this discussion is misguided. What might well be at stake is not so much the nature of the neutral stimulus itself, but its relative saliency as a particular kind of stimulus within the entire list of stimuli. This saliency is in part determined by the multiple repetition of the stimulus and in part by its probability of occurrence. These two factors make the neutral stimulus a distinct event during the experiment, and this distinctiveness results in differential processing. This possibility has been speculatively mentioned in the literature (e.g., De Groot, 1983; Jonides \& Mack, 1984; Shelton \& Martin, 1992). The present ERP data provide the first firm evidence that neutral primes can indeed be less neutral than one might want.

\section{Priming Mechanisms and Task Effects}

One of the most striking aspects of the current results is the processing difference observed between the lexical decision and the silent reading tasks at the level of the N400 to the target words. In the lexical decision task the amplitude of the N400 is modulated by the proportion of related word pairs in the list, whereas in the silent reading task no statistically significant modulation occurs. At the same time, both tasks show N400 effects of semantic relatedness: The amplitude of the N400 to unrelated target words is larger than the amplitude to related words. This latter finding demonstrates that in both of the ERP experiments subjects were engaged in the conjoint processing of the meaning aspects of the primes and targets and that the priming mechanism responsible for bringing about this semantic effect is reflected in the N400, independently of the particular task requirements. It would seem then that the N400 effects due to relatedness proportion arise from a priming mechanism that, in the context of the word priming studies presented in this paper, is specific to the lexical decision task.

The accepted explanation for relatedness proportion effects is to posit an expectancy-induced priming mechanism (cf. Neely \& Keefe, 1989). That is, the presence of a relatively high proportion of related word pairs induces subjects to use a strategy in which they generate an expectancy on the basis of the meaning of the prime about which target word(s) will follow. If this expectancy is met, then processing of the target word will be facilitated rela- 
tive to a neutral baseline, and the processing of unrelated (i.e., unexpected) targets will be inhibited. In lists with a relatively low proportion of related word pairs, expectancies are not generated, and hence no inhibition effect for unrelated word pairs relative to a neutral baseline is predicted. This is exactly the pattern of results obtained in the RT data of the lexical decision experiment. It can, therefore, be confidently claimed that an expectancy-induced priming mechanism was instantiated by the subjects while reading the high relatedness proportion list during the lexical decision experiment.

Two main points, then, emerge from the differential pattern of N400 effects for the lexical decision and silent reading experiments. First, the N400 is sensitive to expectancy-induced priming. This finding has implications for characterizing the processing nature of the N400. Second, expectancy-induced priming as brought about by manipulating relatedness proportion is not a standard aspect of the language comprehension process. This finding has implications for the inferences that can be made from (lexical decision) $\mathrm{RT}$ data to the process of online language comprehension. Each conclusion will be expanded on in turn.

\section{The Processing Nature of the N400}

What processes are reflected by the N400 effect in the silent reading task? Given the absence of a relatedness proportion effect in this task, expectancyinduced priming can be ruled out. Previous research by Brown and Hagoort (1993) has shown that under conditions of masked priming no N400 effect is obtained (yet RTs do reflect semantic priming even when masked). Masking prevents conscious identification and, hence, eliminates strategies such as expectancy and semantic matching (cf. Holender, 1986; Marcel, 1983; Neely, 1991). Masking thereby enables a relatively uncontaminated assessment of the process of automatic spreading of activation. The absence of N400 effects under masking conditions of the prime, therefore demonstrates that automatic spreading of activation is not reflected in the N400. Besson, Fischler, Boaz, and Raney (1992) and Kutas and Hillyard (1989) have presented data on the basis of which they claim that automatic spreading of activation does emerge in the N400. However, their results can also be explained by other priming mechanisms and do not necessitate an explanation in terms of automatic processes (see Chwilla, Brown, \& Hagoort, 1995, for an extended discussion of this issue).

In terms of the three semantic priming mechanisms discussed earlier, only semantic matching remains as the eliciting factor for the semantic priming ERP effect in the silent reading data. This fits well with assumptions concerning the processes that are operative during silent reading. Given that the subject is not confronted with extraneous task demands, all he/she has to do is to read the letter strings. Subjects are engaged in the reading process and as part of the lexical analysis process gain access to the meaning of the 
individual words. The N400 effect reflects the fact that subjects engage in a matching process based on the meanings of the words of each pair. Even in the absence of overt task performance, it appears that an attempt to bridge the meanings of the two words is a standard operation of the comprehension process. This makes sense when it is considered that constructing a coherent higher order meaning representation is one of the most basic characteristics of ordinary language comprehension.

On a more general level, the following picture emerges from the present and previous findings with respect to the processing nature of the N400. First, N400 amplitude is not modulated by the automatic process of spreading activation in the semantic lexicon (cf. Brown \& Hagoort, 1993). Second, the controlled process of expectancy-induced priming does emerge in the amplitude of the N400. However, this is not a general but a task-specific effect. Third, a semantic matching process underlies the N400 effect in the silent reading data. Combining these three findings leads to the conclusion that outside of possible task contamination effects (which can be avoided as the present research has shown), the N400 effect is primarily a reflection of those lexical processes that are involved in semantic integration, either at the word-word level or at the level of higher order sentential semantics (cf. Brown \& Hagoort, 2000; Chwilla et al., 1995; Chwilla, Hagoort, \& Brown, 1998; Hagoort, Brown, \& Groothusen, 1993; Holcomb, 1993; Kellenbach \& Michie, 1996; Polich, 1985b; Rugg, Furda, \& Lorist, 1988).

\section{Effects Specific to Reaction-time Tasks}

Turning to the implications of the second main conclusion that follows from the present results, the ERP data provide a novel line of evidence concerning the impact of task-specific effects. In particular, the link between lexical decision RT data and online language comprehension processes is shown to be problematic, in as far as the relatedness proportion effect is concerned.

On the basis of the fact that a relatedness proportion effect is observed at the level of the N400 in the lexical decision task, but not in the silent reading task, it can be claimed that expectancy-induced priming is not a standard aspect of the language comprehension process. Note that in principle there is no reason why in the silent reading task subjects should not instantiate an expectancy-induced priming mechanism. After all, subjects are confronted with exactly the same list of stimuli as in the lexical decision experiment, and, as is shown by the significant N400 effect between related and unrelated targets, subjects are processing the stimuli at a semantic level during silent reading. The absence of a relatedness proportion effect in the silent reading task, therefore, does strongly imply that the specific mechanism of expectancy-induced priming is not operative during silent reading, and hence that in the present experiment the task characteristics of lexical decision are re- 
sponsible for instantiating expectancy-induced priming. It should be noted here that these task characteristics are probably not specific to lexical decision, since relatedness proportion RT effects have also been reported when using the pronunciation task (cf. Keefe \& Neely, 1990). In other words, the presence of a binary decision component in the lexical decision task is insufficient explanation for the occurrence of expectancy-induced effects. Speed might be a contributing factor, since this is shared by both the lexical decision and the pronunciation tasks (at least in its immediate articulation variant). An emphasis on speed could incline subjects to invoke any kind of strategy that can assist them. In the case of lexical decision, predicting which word will appear on the basis of the meaning of a prime can assist the lexical decision if the prediction turns out to be correct. This will generally be the case in a list with a high proportion of related word pairs. Under the assumption that the silent reading lexical priming paradigm shares aspects of the normal reading process, the current data show that an expectancy strategy of predicting what word(s) will follow a given word is not a standard part of the reading process.

Further research is required to exactly pinpoint the factor(s) involved in bringing about expectancy-induced priming effects. The present data provide evidence that these effects most likely do not reflect normal lexical processing.

\section{REFERENCES}

Becker, C. A. 1980. Semantic context effects in visual word recognition: An analysis of strategies. Memory \& Cognition, 8, 493-512.

Besner, D., \& Johnson, J. C. 1989. Reading and the mental lexicon: On the uptake of visual information. In W. D. Marslen-Wilson (Ed.), Lexical representation and process. Cambridge, MA: MIT Press. Pp. 291-316.

Besson, M., Fischler, I., Boaz, T., \& Raney, G. 1992. Effects of automatic associative activation on explicit and implicit memory tests. Journal of Experimental Psychology: Learning, Memory, and Cognition, 18, 89-105.

Besson, M., \& Kutas, M. 1993. The many facets of repetition: A cued-recall and event-related potential analysis of repeating words in same versus different sentence contexts. Journal of Experimental Psychology: Learning, Memory, and Cognition, 19, 1115-1133.

Brown, C. M., \& Hagoort, P., 1993. The processing nature of the N400: Evidence from masked priming. Journal of Cognitive Neuroscience, 5, 34-44.

Brown, C. M., \& Hagoort, P. 2000. On the electrophysiology of language processing: Implications for the human language processor. In M. W. Crocker, M. J. Pickering, \& C. J. Clifton (Eds.), Architectures and mechanisms for language processing. Cambridge: Cambridge Univ. Press. Pp. 213-237.

Brunia, C. H. M. 1988. Movement and stimulus preceding negativity. Biological Psychology, 26, 165-178.

Brunia, C. H. M. 1993. Waiting in readiness: Gating in attention and motor preparation. Psychophysiology, 30, 327-339. 
Bush, L. K., Hess, U., \& Wolford, G. 1993. Transformations for within-subject designs: A Monte Carlo investigation. Psychological Bulletin, 113, 566-579.

Chwilla, D. J., Brown, C. M., \& Hagoort, P. 1995. The N400 as a function of the level of processing. Psychophysiology, 32, 274-285.

Chwilla, D. J., Hagoort, P., \& Brown, C. M. 1998. The mechanism underlying backward primingin lexical decision: Spreading activation versus semantic matching. Quarterly Journal of Experimental Psychology, 51A, 531-560.

Collins, A. M., \& Loftus, E. F. 1975. A spreading-activation theory of semantic processing. Psychological Review, 82, 407-428.

De Groot, A. M. B. 1980. Mondelinge woordassociatienormen. Lisse: Swets \& Zeitlinger.

De Groot, A. M. B. 1983. The range of automatic spreading activation in word priming. Journal of Verbal Learning and Verbal Behavior, 22, 417-436.

De Groot, A. M. B. 1984. Primed lexical decision: Combined effects of the proportion of related prime-target pairs and the stimulus-onset asynchrony of prime and target. Quarterly Journal of Experimental Psychology, 36A, 253-280.

De Groot, A. M. B., Thomassen, A. J. W. M., \& Hudson, P. T. W. 1982. Associative facilitation of word recognition as measured from a neutral prime. Memory \& Cognition, 10, 358370.

Den Heyer, K., Briand, K., \& Dannebring G. 1983. Strategic factors in a lexical decision task: Evidence for automatic and attention-driven processes. Memory \& Cognition, 11, 374381.

Fabiani, M., Gratton, G., Karis, D., \& Donchin, E. 1987. Definition, identification, and reliability of measurement of the P300 component of the event-related brain potential. In P. K. Ackles, J. R. Jennings, \& M. G. H. Coles (Eds.), Advances in psychophysiology. Vol. 2. Greenwich, CT: JAI Press. Pp. 1-78.

Fischler, I. 1977. Associative facilitation without expectation in a lexical decision task. Journal of Experimental Psychology: Human Perception and Performance, 3, 18-26.

Fischler, I., \& Bloom, P. A. 1980. Rapid processing of the meaning of sentences. Memory \& Cognition, 8, 216-225.

Fodor, J. A. 1983. The modularity of mind: An essay on faculty psychology. Cambridge, MA: MIT Press.

Hagoort, P., Brown, C. M., \& Groothusen, J. 1993. The Syntactic Positive Shift (SPS) as an ERP-measure of syntactic processing. Language and Cognitive Processes, 8, 439-483.

Holcomb, P. J. 1988. Automatic and attentional processing: An event-related brain potential analysis of semantic priming. Brain and Language, 35, 66-85.

Holcomb, P. J. 1993. Semantic priming and stimulus degradation: Implications for the role of the N400 in language processing. Psychophysiology, 30, 47-61.

Holender, D. 1986. Semantic activation without conscious identification in dichotic listening, parafoveal vision, and visual masking: A survey and appraisal. Behavioral and Brain Sciences, 9, 1-23.

Jasper, H. H. 1958. The ten-twenty electrode system of the International Federation. Electroencephalography \& Clinical Neurophysiology, 10, 371-375.

Jonides, J., \& Mack, R. 1984. On the cost and benefit of cost and benefit. Psychological Bulletin, 96, 29-44.

Keefe, D. E., \& Neely, J. H. 1990. Semantic priming in the pronunciation task: The role of prospective prime-generated expectancies. Memory \& Cognition, 18, 289-298.

Kellenbach, M. L., \& Michie, P. T. 1996. Modulation of event-related potentials by semantic 
priming: Effects of color-cued selective attention. Journal of Cognitive Neuroscience, $\mathbf{8}$, $155-173$.

Koyama, S., Nageishi, Y., \& Shimokochi, M. 1992. Effects of semantic context and eventrelated potentials: N400 correlates with inhibition effect. Brain and Language, 43, 668681.

Kutas, M., \& Hillyard, S. A. 1980. Reading senseless sentences: Brain potentials reflect semantic incongruity. Science, 207, 203-205.

Kutas, M., \& Hillyard, S. A. 1989. An electrophysiological probe of incidental semantic association. Journal of Cognitive Neuroscience, 1, 38-49.

Kutas, M., \& Van Petten, C. 1988. Event-related brain potential studies of language. In P. K. Ackles, J. R. Jennings, \& M. G. H. Coles (Eds.), Advances in psychophysiology. Vol. 3. Greenwich, CT: JAI Press. Pp. 139-187.

Kutas, M., \& Van Petten, C. 1994. Psycholinguistics electrified: Event-related brain potential investigations. In M. Gernsbacher (Ed.), Handbook of psycholinguistics. New York: Academic Press.

Lauteslager, M., Schaap, T., \& Schievels, D. 1986. Schriftelijke woordassociatienormen voor 549 nederlandse zelfstandige naamwoorden. Lisse: Swets \& Zeitlinger.

Lorch, R. F. Jr. 1986. Use of a word reading task for studying word recognition. Bulletin of the Psychonomic Society, 24, 11-14.

Marcel, A. J. 1983. Conscious and unconscious perception: Experiments on visual masking and word recognition. Cognitive Psychology, 15, 197-237.

McCarthy, G., \& Wood, C. C. 1985. Scalp distributions of event-related potentials: An ambiguity associated with analysis of variance models. Electroencephalography \& Clinical Neurophysiology, 62, 203-208.

McNamara, T. P., \& Healy, A. F. 1988. Semantic, phonological, and mediated priming in reading and lexical decisions. Journal of Experimental Psychology: Learning, Memory, and Cognition, 14, 398-409.

Neely, J. H. 1977. Semantic priming and retrieval from lexical memory: Roles of inhibitionless spreading activation and limited-capacity attention. Journal of Experimental Psychology: General, 106, 226-254.

Neely, J. H. 1991. Semantic priming effects in visual word recognition. A selective review of current findings and theories. In D. Besner \& G. Humphreys (Eds.), Basic processes in reading: Visual word recognition. Hillsdale, NJ: Erlbaum. Pp. 264-336.

Neely, J. H., \& Keefe, D. E. 1989. Semantic context effects on visual word processing: A hybrid prospective/retrospective processing theory. In G. H. Bower (Ed.), The psychology of learning and motivation: Advances in research and theory. Vol. 24. New York: Academic Press. Pp. 207-248.

Neely, J. H., Keefe, D. E., \& Ross, K. L. 1989. Semantic priming in the lexical decision task: Roles of prospective prime-generated expectancies and retrospective semantic matching. Journal of Experimental Psychology: Learning, Memory, and Cognition, 15, 1003-1019.

Oldfield, R. C. 1971. The assessment and analysis of handedness: The Edinburgh inventory. Neuropsychologia, 9, 97-113.

Polich, J. 1985a. N400s from sentences, semantic categories, number and letter strings? Bulletin of the Psychonomic Society, 23, 361-364.

Polich, J. 1985b. Semantic categorization and event-related potentials. Brain and Language, 26, 304-321.

Pritchard, W. S., Shappell, S. A., \& Brandt, M. E. 1991. Psychophysiology of N200/N400: A review and classification scheme. In P. K. Ackles, J. R. Jennings, \& M. G. H. Coles (Eds.), Advances in psychophysiology, Vol. 4. London: Jessica Kingsley. Pp. 43-106. 
Ritter, W., Ford, J. M., Gaillard, A. W. K., Harter, M. R., Kutas, M., Näätänen, R., Polich, J., Renault, B., \& Rohrbaugh, J. 1984. Cognition and event-related potentials: I. The relation of negative potentials and cognitive processes. In R. Karrer, J. Cohen, \& P. Tueting (Eds.), Brain and information: Event-related potentials. New York: New York Acad. of Sci. Pp. 24-38.

Rösler, F., Sutton, S., Johnson, R., Mulder, G., Fabiani, M., Plooij-van Goorsel, E., \& Roth, W. T. 1986. Endogenous ERP components and cognitive constructs: A review. In W. C. McCallum, R. Zappoli, \& F. Denoth (Eds.). Cerebral psychophysiology: Studies in eventrelated potentials (EEG Suppl. 38). Amsterdam: Elsevier. Pp. 51-92.

Rösler, F., Heil, M., \& Glowalla, U. 1993. Monitoring retrieval from long-term memory by slow event-related potentials. Psychophysiology, 30, 170-182.

Ruchkin, D. S., Johnson, R., Mahaffey, D., \& Sutton, S. 1988. Toward a functional categorization of slow waves. Psychophysiology, 25, 339-353.

Rugg, M. D. 1985. The effects of semantic priming and word repetition on event-related potentials. Psychophysiology, 22, 642-647.

Rugg, M. D. 1987. Dissociation of semantic priming, word and non-word repetition effects by event-related potentials. Quarterly Journal of Experimental Psychology, 39A, 123148.

Rugg, M. D., \& Doyle, M. C. 1992. Event-related potentials and recognition memory for lowand high-frequency words. Journal of Cognitive Neuroscience, 4, 69-79.

Rugg, M. D., Furda, J., \& Lorist, M. 1988. The effects of task on the modulation of eventrelated potentials by word repetition. Psychophysiology, 25, 55-63.

Seidenberg, M. S. 1989. Visual word recognition and pronunciation: A computational model and its implications. In W. D. Marslen-Wilson (Ed.), Lexical representation and process. Cambridge, MA: MIT Press. Pp. 25-74.

Seidenberg, M. S., Waters, G. S., Sanders, M., \& Langer, P. 1984. Pre- and postlexical loci of contextual effects on word recognition. Memory \& Cognition, 12, 315-328.

Shelton, J. R., \& Martin, R. C. 1992. How semantic is automatic semantic priming? Journal of Experimental Psychology: Learning, Memory, and Cognition, 18, 1191-1210.

Tweedy, J. R., Lapinski, R. H., \& Schvaneveldt, R. W. 1977. Semantic-context effects on word recognition: Influence of varying the proportion of items in an appropriate context. Memory \& Cognition, 5, 84-99.

Uit den Boogaart, P. C. 1975. Woordfrequenties. Utrecht: Oosthoek, Scheltema \& Holkema.

Van Petten, C., Kutas, M., Kluender, R., Mitchiner, M., \& McIsaac, H. 1991. Fractionating the word repetition effect with event-related potentials. Journal of Cognitive Neuroscience, $\mathbf{3}$, $131-150$.

Winer, B. J. 1971. Statistical principles in experimental design. Tokyo: McGraw-Hill Kogakusha. 